\title{
Diagnostic accuracy of staging of Wilms' tumour in the era of multislice CT
}

\author{
S Kembhavi", S Qureshi, M Ramadwar, P Popat, G Chinnaswamy, S Laskar \\ From International Cancer Imaging Society (ICIS) 14th Annual Teaching Course \\ Heidelberg, Germany. 9-11 October 2014
}

\section{Aim}

To assess the diagnostic accuracy of $\mathrm{CT}$ in local staging of Wilms' Tumour.

\section{Method}

Audit of radiology reports (16 slice CT), surgical notes and histopathological reports in 24 cases of unilateral non-metastatic Wilms' tumour (2012 to 2014).

\section{Results}

24 patients were eligible. 12 boys, 12 girls, age range of 1-10 years (mean 3.9). 6 patients underwent upfront surgery (Group A) while 18 patients received 4 weeks of chemotherapy (Group B). The post chemotherapy scans were compared to gold standard in the latter group.

Renal vein involvement: Present in 8 patients (all group B), CT had 100\% sensitivity, $90 \%$ specificity, NPV $100 \%$.

Renal sinus involvement: Present in 14 patients (4 group A, 10 group B). Sensitivity and specificity of CT was $25 \%, 100 \%$ for group A and $90 \%, 50 \%$ for group B.

Renal pelvis involvement: Present in 8 patients (1 group A, 7 group B). Sensitivity and specificity of CT was $71.4 \%, 81.8 \%$ for group B and specificity of $100 \%$ for group A.

Renal Capsular involvement (but not necessarily the margin) was present in 6 patients (2 group A, 4 group B). Sensitivity and specificity of CT was $50 \%, 100 \%$ for group A and $42.8 \%, 75 \%$ for group B.

Overall, CT stage matched histopathological stage in $4 / 6$ patients in group A and in 12/18 patients in group B (66.6\% in both groups).

* Correspondence: seema.kembhavi@gmail.com

Tata Memorial Centre, Mumbai, India

C 2014 Kembhavi et al: licensee BioMed Central Ltd. This is an Open Access article distributed under the terms of the Creative Commons Attribution License (http://creativecommons.org/licenses/by/4.0), which permits unrestricted use, distribution, and reproduction in any medium, provided the original work is properly cited. The Creative Commons Public Domain Dedication waiver (http://creativecommons.org/publicdomain/zero/1.0/) applies to the data made available in this article, unless otherwise stated.
doi:10.1186/1470-7330-14-S1-P18
Cite this article as: Kembhavi et al.: Diagnostic accuracy of staging of
Wilms' tumour in the era of multislice CT. Cancer Imaging 2014 14(Suppl 1):P18. and take full advantage of:

- Convenient online submission

- Thorough peer review

- No space constraints or color figure charges

- Immediate publication on acceptance

- Inclusion in PubMed, CAS, Scopus and Google Scholar

- Research which is freely available for redistribution
CT staging has higher specificity in upfront surgery, probably because of the smaller tumour size. The sensitivity of involvement is better than renal capsular involvement, where CT tends to over-stage disease in larger tumours.

\section{Conclusion}

Published: 9 October 2014 